
\title{
BReserch S Suare \\ Inhibitory efficiency evaluation of the phenazopyridine tablet for mild steel corrosion in acidic media
}

Razieh Naghizade

Shahid Bahonar University of Kerman

Ghazal Sadat Sajadi

Shahid Bahonar University of Kerman

Zahra Golshani

Shahid Bahonar University of Kerman

Seyed Mohammad Ali Hosseini ( $\sim$ S.M.A.Hosseini@uk.ac.ir)

Shahid Bahonar University of Kerman

\section{Research Article}

Keywords: Corrosion inhibitor, Adsorption, Electrochemical impedance spectroscopy, Potentiodynamic polarization, Phenazopyridine tablet

Posted Date: March 1st, 2022

DOI: https://doi.org/10.21203/rs.3.rs-1388154/v1

License: (9) This work is licensed under a Creative Commons Attribution 4.0 International License. Read Full License 


\section{Abstract}

The inhibition performance of phenazopyridine tablet on mild steel in $0.5 \mathrm{M}$ phosphoric acid and $1 \mathrm{M}$ hydrochloric acid solutions is investigated using different techniques (potentiodynamic polarization, electrochemical impedance spectroscopy (EIS)) and scanning electronic microscopy (SEM)). The gained results demonstrated that various concentrations of phenazopyridine inhibited the corrosion of the alloy in both of the acid solutions. The inhibition efficiency raised with a rise in the concentration of the drug and reduced with a rise in temperature. The maximum inhibition efficiency is observed in the presence of $500 \mathrm{ppm}$ of the compound. Polarization evaluations displayed that the phenazopyridine acts as a mixed inhibitor in the hydrochloric acid solution and acts as an anodic inhibitor in the phosphoric acid solution. The corrosion parameters derived from the techniques are agreeing with one another. The adsorption mechanism of the tablet on the alloy was investigated by the Langmuir adsorption isotherm. The entropy of adsorption increased in hydrochloric acid and decreased in phosphoric acid solution. SEM micrographs were taken from the surface of the mild steel after exposure.

\section{Introduction}

The corrosion of metals is a worldwide problem in many manufacturing industries [1]. mild steel extensively employed in various manufacturing industries such as gas and oil where acid pickling, acid descaling, chemical cleaning, oil well acidizing is commonly performed [2]. However, this material undergoes a significant disadvantage due to inadequate corrosion resistor in acidic media [3]. The alloys corrosion can be controlled, decelerated or even completely stopped by using proper methods such as protective coatings and organic or inorganic inhibitors [4-7].

Referring to the writings, the most useful corrosion inhibitors are organic compounds with hetero-atoms $(\mathrm{N}, \mathrm{O}$, and $\mathrm{S})$ and $\mathrm{J}$-bonds in their molecular structures $[8,9]$. But, the poisonous industrial corrosion inhibitors results in contamination of the surroundings [10]. Therefore, the theory of "Green Chemistry" was suggested, and the natural and biodegradable chemicals that are not harmful to the surroundings have become an attention to stop the corrosion of industrial facilities recently [10]. In new year's scientists have paid considerable care to the growth of antibacterial medicines as inhibitors for metallic corrosion [11-17]. Most of the compounds are nontoxic and inexpensive with minor adverse effects on the environment, replacing the old toxic corrosion inhibitors [18]. Therefore, in this study is evaluated the inhibition role of phenazopyridine tablet on corrosion of mild steel alloy in $0.5 \mathrm{M} \mathrm{H}_{3} \mathrm{PO}_{4}$ and $1.0 \mathrm{M} \mathrm{HCl}$ environments by potentiodynamic polarization, electrochemical impedance spectroscopy (EIS), and scanning electron microscopy(SEM).

\section{Experimental}

\subsection{Materials and solutions}


The molecular structure of phenazopyridine used in this study is given in Fig. 1. The analytical grade $85 \%$ $\mathrm{H}_{3} \mathrm{PO}_{4}, 37 \% \mathrm{HCl}$ and distilled water were used for acquiring $0.5 \mathrm{M}$ phosphoric acid and $1 \mathrm{M}$ hydrochloric acid. The concentration of inhibitor utilized was 100,200,300, 400, 500 and 600 ppm in both acid solutions. The $1 \mathrm{~cm}^{2}$ mild steel specimens were employed having the composition (wt. \%): Fe $97.84 \%, \mathrm{Mn}$ $1.4 \%$, Se 0.5 , C $0.17 \%$, P $0.045 \%$ and S $0.045 \%$. Before all measurements, the specimens were polished with different grades of sand-paper (200 to 3000), then washing with distilled water, finally dried in the air.

\subsection{Procedures}

\subsubsection{Electrochemical measurements}

Three-electrode cells containing $\mathrm{Ag} / \mathrm{AgCl}$ electrode, Pt electrode, and mild steel were utilized as a reference electrode, a counter electrode and the working electrode for this study, respectively. The polarization scan rate was set $1 \mathrm{mV} / \mathrm{s}$ to plot the Tafel polarization curves. The -200 to $+200 \mathrm{mV}$ potential range and The $100 \mathrm{mHz}$ to $100 \mathrm{kHz}$ frequency range were used for potentiodynamic polarization tests and EIS tests, respectively. Before each polarization and, the impedance test, the potential was stabled within 30 minute. The temperature was $25 \pm 1^{\circ} \mathrm{C}$. Eventually, all of the curves analyzed with Nova software

\subsubsection{Effect of temperature}

The effect of temperature on the corrosion rate of mild steel in $0.5 \mathrm{M} \mathrm{H}_{3} \mathrm{PO}_{4}$ and $1 \mathrm{M} \mathrm{HCl}$ environments in the absence and presence of various concentrations of drug in the $25-55 \pm 1^{\circ} \mathrm{C}$ temperature range was studied by potentiodynamic polarization method.

\subsubsection{Surface morphology studies}

Scanning electron microscopic (SEM) was used for investigating the surface morphology of the working electrode after plunging of the alloy for 24 hours in both of the solutions at room temperature, without and with optimum concentration of phenazopyridine.

\section{Results And Discussion}

\subsection{Potentiodynamic Polarization}

Potentiodynamic polarization measurements were utilized to examine the effect of inhibition concentration on the corrosion of mild steel alloy in $0.5 \mathrm{M} \mathrm{H}_{3} \mathrm{PO}_{4}$ and $1.0 \mathrm{M} \mathrm{HCl}$ environments without and with various concentrations of phenazopyridine. This study revealed that when the concentration of the inhibitor increased up to $500 \mathrm{ppm}$ in phosphoric acid and hydrochloric acid, inhibition efficiency increased, in higher concentrations (above $500 \mathrm{ppm}$ ) the inhibition efficiency decreased. Figure 2 illustrates, the plots obtained from these experiments for the acidic environments. To do more precise measurements, polarization plots were analyzed. Table 1 presents the electrochemical parameters including; corrosion potential $\left(\mathrm{E}_{\mathrm{corr}}\right)$, Corrosion current density $\left(\mathrm{j}_{\mathrm{corr}}\right)$, cathodic Tafel slope $(\beta c)$, Anodic 
Tafel slope $(\beta a)$, surface coating $(\theta)$, inhibitory percentage (IE \%) obtained from the polarization measurements.

Table 1

Electrochemical parameters obtained from polarization curves for mild steel in a) phosphoric acid and b) hydrochloric acid solution in absence and presence of different concentrations of inhibitor at $25 \pm 1^{\circ} \mathrm{C}$.

\begin{tabular}{|c|c|c|c|c|c|c|c|}
\hline \multirow{2}{*}{$\begin{array}{l}\text { C/ppm } \\
\text { (a) H3PO }\end{array}$} & \multicolumn{2}{|c|}{$\mathrm{j}_{\mathrm{corr}} / \mu \mathrm{A} \cdot \mathrm{cm}^{-2}$} & \multirow[t]{2}{*}{$-\mathrm{E}_{\mathrm{corr}} / \mathrm{mV}$} & \multirow[t]{2}{*}{$\beta_{\mathrm{c}} / \mathrm{mV} \cdot \mathrm{dacade}^{-1}$} & \multirow[t]{2}{*}{$\beta_{\mathrm{a}} / \mathrm{mV}$. dacade $^{-1}$} & \multirow[t]{2}{*}{$\theta$} & \multirow[t]{2}{*}{ IE\% } \\
\hline & & & & & & & \\
\hline Blank & 638 & 376 & & 111 & 101 & $\ldots \ldots$ & ....... \\
\hline 100 & 265 & 305 & & 130 & 77 & 0.58 & 58 \\
\hline 200 & 180 & 340 & & 128 & 66 & 0.72 & 72 \\
\hline 300 & 157 & 319 & & 116 & 66 & 0.75 & 75 \\
\hline 400 & 138 & 332 & & 135 & 53 & 0.78 & 78 \\
\hline 500 & 64 & 318 & & 140 & 41 & 0.90 & 90 \\
\hline 600 & 147 & 313 & & 48 & 163 & 0.77 & 77 \\
\hline \multicolumn{8}{|l|}{ (b) $\mathrm{HCl}$} \\
\hline Blank & 1318 & 491 & & 128 & 108 & $\ldots \ldots$ & $\ldots \ldots$ \\
\hline 100 & 492 & 487 & & 124 & 105 & 0.62 & 62 \\
\hline 200 & 301 & 483 & & 111 & 91 & 0.77 & 77 \\
\hline 300 & 278 & 484 & & 93 & 91 & 0.79 & 79 \\
\hline 400 & 245 & 476 & & 121 & 90 & 0.81 & 81 \\
\hline 500 & 200 & 475 & & 112 & 84 & 0.85 & 85 \\
\hline 600 & 239 & 470 & & 118 & 80 & 0.82 & 82 \\
\hline
\end{tabular}

The inhibitory efficiency is obtained through the following equation [19] :

$\mathrm{IE} \%=\left(\frac{\mathrm{j}_{\text {corr }}-\mathrm{j}_{\text {inh }}}{\mathrm{j}_{\text {corr }}}\right) \times 100(1)$

Where, $\mathrm{j}_{\text {corr }}$ and $\mathrm{j}_{\mathrm{inh}}$ represent the current density in the absence and presence of inhibitor that was acquired by extrapolating Tefal lines of polarization plots. The corrosion current density decreased in the phosphoric acid and hydrochloric acid, when the drug concentration grows up to $500 \mathrm{ppm}$, suggesting that this tablet acts as a corrosion inhibitor and when it is adsorbed on the metal surface; it can form a 
protective layer. The increase in the inhibitory efficiency when the concentration increased indicated that this protective layer can be formed at higher concentrations [20]. Generally, if open circuit potential or corrosion potential is lowered to more active (negative) values, it suggests the inhibitory function in cathodic form, and any changes toward the positive direction show the anodic inhibitory process. The mixed inhibitors usually do not significantly change the corrosion potential. The investigations show that the corrosion potential does not change significantly when the concentrations of inhibitor in the hydrochloric acid environment increased, which indicates the function of this tablet as a mixed inhibitor. However, in the phosphoric acid, the corrosion potential changed slightly toward the positive direction, showing the anodic behavior of the inhibitor [21]. The phenazopyridine tablet blocked both the anodic and cathode regions in hydrochloric acid, while in the phosphoric acid, it was adsorbed in the anodic regions. Consequently, a protective film was formed on the surface, which reduced the current density and rate of corrosion.

\subsection{Electrochemical Impedance Spectroscopy}

To study the adsorption mechanism, EIS tests were performed with and without different inhibitory concentrations on mild steel in both acidic media. Figure 3 shows Nyquist plots derived from these tests. It can be seen that as the inhibitor was added to hydrochloric and phosphoric acid in a concentration of $500 \mathrm{ppm}$, an increase in diameter of Nyquist plots resulted, which led to the increase in charge transfer resistance $\left(R_{c t}\right)$. The values of the $R_{c t}$ is obtained due to the difference in impedance at high and low frequencies.

The inhibition efficiency can be calculated using the below equation [22] :

$I E \%=\left(\frac{R_{i}-R_{o}}{R_{i}}\right) \times 100(2)$

Where $\mathrm{R}_{\mathrm{o}}$ and $\mathrm{R}_{\mathrm{i}}$ are respectively the charge transfer resistance in an acid solution in the absence and presence of the inhibitor.

To perform a more precise analysis of electrochemical impedance plots, the plots were simulated and evaluated regarding the equivalent circuit shown in Fig. 4. In this Figure; $R_{s}$ is the solution resistance, $R_{c t}$ is charge transfer resistance. The impedance of the constant phase element (CPE) is expressed as follows [23] :

$\mathrm{Z}_{\mathrm{CPE}}=A^{-1}(\mathrm{i} \omega)^{-\mathrm{n}}(3)$

Where $A$ is the coefficient of proportion, $\omega$ is the angular frequency, $i^{2}=-1$, and $n$ is the coefficient of surface toughness. When $n=1, C P E$ acts similar to a pure capacitor.

Double-layer capacitance can be obtained through the formula [24]: 
$\mathrm{C}_{\mathrm{dl}}=A\left(\omega_{\max }\left({ }^{\mathrm{n}-1}(4)\right.\right.$

$\mathrm{C}_{\mathrm{dl}}$ is the double layer capacitance, and $\omega_{\max }$ is the maximum frequency obtained from the Nyquist plot for each analysis.

The results obtained from the Nyquist plot are inserted in Table 2. As observed, in the chloride acid and phosphoric acid media, by increasing the inhibitory concentration up to $500 \mathrm{ppm}$, the charge transfer resistance and inhibition efficiency increased. In Contrast, double layer capacitance decreased through the adsorption of the inhibitor on the surface. The data obtained from polarization measurements were consistent with impedance data.

Table 2

Corrosion parameters obtained from Nyquist curves for mild steel in $\mathrm{H}_{2} \mathrm{SO}_{4}$ in a) phosphoric acid and b) presence of different concentrations of Thyme at $25 \pm 1^{\circ} \mathrm{C}$.

\begin{tabular}{|llllll|}
\hline C/ppm & $R_{\text {ct }} / \Omega . \mathrm{cm}^{2}$ & $\mathbf{n}$ & $10^{6} \mathrm{~A} / \mathrm{F} \mathrm{cm}^{-2} \mathbf{s}^{\mathrm{n}-1}$ & $\mathrm{C}_{\mathrm{dl}} / \mu \mathrm{F} . \mathrm{cm}^{-2}$ & $\mathrm{IE} \%$ \\
\hline a) H3PO4 & & & & & \\
\hline Blank & 16 & 0.80 & 375 & 116 & $\ldots$ \\
\hline 100 & 53 & 0.85 & 157 & 66 & 70 \\
\hline 200 & 69 & 0.86 & 154 & 77 & 77 \\
\hline 300 & 95 & 0.90 & 101 & 60 & 83 \\
\hline 400 & 114 & 0.86 & 119 & 66 & 86 \\
\hline 500 & 247 & 0.89 & 52 & 29 & 93 \\
\hline 600 & 159 & 0.87 & 83 & 46 & 90 \\
\hline b) HCl & & & & & \\
\hline Blank & 10 & 0.85 & 616 & 246 & $\ldots$ \\
\hline 100 & 27 & 0.84 & 420 & 177 & 63 \\
\hline 200 & 42 & 0.86 & 264 & 130 & 76 \\
\hline 300 & 52 & 0.82 & 345 & 147 & 81 \\
\hline 400 & 65 & 0.86 & 220 & 110 & 84 \\
\hline 500 & 79 & 0.86 & 175 & 89 & 87 \\
\hline 600 & 63 & 0.83 & 261 & 114 & 84 \\
\hline
\end{tabular}

\subsection{Adsorption Isotherm}


The mechanism of adsorption of inhibitors depends on several factors, such as: material type, surface charges, corrosive environment, ambient $\mathrm{pH}$, inhibitor concentration, charge distribution on the inhibitor, as well as functional groups on the inhibitory molecule [25]. Usually, there are two types of adsorption, physical adsorption that requires a charged metal area and charged species in the solution, and chemical adsorption in which electron sharing or the transfer of electrons between the inhibitor species can be seen. For this kind of adsorption, an inhibitor with a lone pair or a free electron and an empty orbital metal are required [12].

The most important use of adsorption isotherm in solid-liquid systems is to investigate the effect of the inhibitors. In this case, adsorption compounds show a relationship between the inhibitor on the surface and the soluble mass. It is possible to examine the inhibitory strength on the surface of the alloy. To investigate the adsorption isotherm in both acidic media, different isotherms, such as Langmuir, Temkin, and Freundlich, were checked. The best confirmation was obtained by Langmuir adsorption isotherm for the inhibitor in both media.

Langmuir adsorption isotherm plots are drawn through the following equation [26]:

$$
\frac{\mathrm{C}}{\theta}=\frac{1}{\mathrm{~K}_{\mathrm{ads}}}+\mathrm{C}
$$

5

Where $\mathrm{C}$ is the inhibitory concentration, $\mathrm{K}_{\mathrm{ads}}$ is the constant of adsorption equilibrium, and $\theta$ is the surface coating that is derived through the following formula by using the inhibitory efficiency, which is the result of the potentiodynamic polarization plots:

$\theta=(\mathrm{IE} \%) / 100(6)$

Thus, regarding $\mathrm{C}$ / $\theta$ plot in $\mathrm{C}$, in Eq. 5 , a straight line is obtained, and it depicts that the inhibitor obeys Langmuir adsorption isotherm in these acidic environments (Fig. 5).

\subsection{Temperature Effect}

The effect of temperature on different corrosion parameters, such as corrosion current, corrosion potential, surface coating, and inhibitory percentage in the range of $25-55^{\circ} \mathrm{C}$, is examined in an optimal concentration of the drug. The polarization plots are demonstrated in Fig. 6, and the parameters of the temperature effect investigation are summarized in Table 3. 
Table 3

Corrosion parameters obtained from polarization measurements in $0.5 \mathrm{M}$ $\mathrm{H} 3 \mathrm{PO} 4 \mathrm{a}$ ) without inhibitorb) with $500 \mathrm{ppm}$ of inhibitor and in $1 \mathrm{M} \mathrm{HCl}$ solution c) without inhibitor and d) with $500 \mathrm{ppm}$ of inhibitor, at different temperatures.

\begin{tabular}{|c|c|c|c|}
\hline temperature/ ${ }^{\circ} \mathrm{C}$ & $\mathrm{j}_{\mathrm{corr}} / \mu \mathrm{A} \cdot \mathrm{cm}^{-2}$ & \multicolumn{2}{|l|}{$-\mathrm{E}_{\mathrm{corr}} / \mathrm{mV}$} \\
\hline \multicolumn{4}{|c|}{ (a) H3PO4 without inhibitor } \\
\hline 25 & 638 & \multicolumn{2}{|l|}{376} \\
\hline 35 & 1550 & \multicolumn{2}{|l|}{546} \\
\hline 45 & 1602 & \multicolumn{2}{|l|}{551} \\
\hline 55 & 2305 & \multicolumn{2}{|l|}{552} \\
\hline temperature/ ${ }^{\circ} \mathrm{C}$ & $\mathrm{j}_{\mathrm{corr}} / \mu \mathrm{A} \cdot \mathrm{cm}^{-2}$ & $-\mathrm{E}_{\mathrm{corr}} / \mathrm{mV}$ & $\mathrm{IE} \%$ \\
\hline \multicolumn{4}{|c|}{ (b) H3PO4 with 500 ppm of inhibitor } \\
\hline 25 & 64 & 318 & 90 \\
\hline 35 & 350 & 512 & 77 \\
\hline 45 & 1380 & 520 & 13 \\
\hline 55 & 2100 & 543 & 9 \\
\hline temperature/ ${ }^{\circ} \mathrm{C}$ & $\mathrm{j}_{\text {corr }} / \mu \mathrm{A} \cdot \mathrm{cm}^{-2}$ & \multicolumn{2}{|l|}{$-\mathrm{E}_{\mathrm{corr}} / \mathrm{mV}$} \\
\hline \multicolumn{4}{|c|}{ (c) $\mathrm{HCl}$ without inhibitor } \\
\hline 25 & 1318 & \multicolumn{2}{|l|}{491} \\
\hline 35 & 2973 & \multicolumn{2}{|l|}{483} \\
\hline 45 & 5431 & \multicolumn{2}{|l|}{480} \\
\hline 55 & 9857 & \multicolumn{2}{|l|}{486} \\
\hline temperature/ ${ }^{\circ} \mathrm{C}$ & $\mathrm{j}_{\mathrm{corr}} / \mu \mathrm{A} \cdot \mathrm{cm}^{-2}$ & $-\mathrm{E}_{\mathrm{corr}} / \mathrm{mV}$ & $\mathrm{IE} \%$ \\
\hline \multicolumn{4}{|c|}{ (d) $\mathrm{HCl}$ with $500 \mathrm{ppm}$ of inhibitor } \\
\hline 25 & 200 & 475 & 85 \\
\hline 35 & 544 & 472 & 81 \\
\hline 45 & 2027 & 478 & 62 \\
\hline 55 & 4914 & 472 & 50 \\
\hline
\end{tabular}


The effect of temperature on the metal-acid inhibition is highly complicated because several processes may occur due to temperature rise. For example, an inhibitor adsorbed on the surface of the metal or, the inhibitor decomposition due to the increase in temperature. The temperature rise stead up the oxidation rate and reduction reactions at the metal surface and prevented the formation of a uniform film by the inhibitor. it led to the access of corrosive ions to the surface of the alloy, which increased the corrosion rate [12].

It should be noted that in case the inhibitory inhibition rate reduced with the increased temperature, the physical adsorption of inhibitory molecules on the surface of the metal was resulted. In contrast, if an opposite behaviour took place with the increase in temperature, it could be said that the inhibitor adsorption is chemical. Therefore, since the increased temperature reduced the inhibition levels in hydrochloric and phosphoric acid, it can be noted that inhibition in these two media is mostly physical adsorption on the surface of the alloy [12].

Arrhenius relation is used to show the dependence of the corrosion rate on the temperature [27]:

$\mathrm{j}_{\text {corr }}=\mathrm{A} \exp \left(\frac{-\mathrm{E}_{\mathrm{a}}}{\mathrm{RT}}\right)(7)$

$\mathrm{j}_{\text {corr }}$ is the density of the corrosion current, $\mathrm{A}$ is the frequency factor, $\mathrm{E}_{\mathrm{a}}$ is the activation energy of the metal dissolution reaction, $\mathrm{R}$ is the gas constant $\left(8.314 \mathrm{~J} \cdot \mathrm{K}^{-1} \cdot \mathrm{mol}^{-1}\right)$ and $\mathrm{T}$ is the absolute temperature (K). The activation energy was measured using the slope of the $L n j_{\text {corr }}$ plot versus $1 / T$ (Fig. 7). The estimated activation energies for the inhibitor are given in Table 4. It is understood that the activation energy of the corrosion reaction of the mild steel increases when the inhibitor is added to the solutions.

Table 4

Kinetic and Thermodynamic parameters for adsorption of inhibitor in $\mathrm{H}_{3} \mathrm{PO}_{4}$ and $\mathrm{HCl}$ solutions on the mild steel surface.

\begin{tabular}{|c|c|c|c|c|}
\hline & $\begin{array}{l}\mathrm{E}_{\mathrm{a}} \\
\left(\mathrm{kJ} \cdot \mathrm{mol}^{-1}\right)\end{array}$ & $\begin{array}{l}\Delta \mathrm{H}_{\mathrm{ads}}^{\mathrm{o}} \\
\left(\mathrm{kJ} \cdot \mathrm{mol}^{-1}\right)\end{array}$ & $\begin{array}{l}\Delta \mathrm{G}_{\mathrm{ads}}^{\mathrm{o}} \\
\left(\mathrm{kJ} . \mathrm{mol}^{-1}\right)\end{array}$ & $\begin{array}{l}\Delta \mathrm{S}_{\mathrm{ads}}^{\mathrm{o}} \\
\left(\mathrm{kJ} \cdot \mathrm{mol}^{-1} \cdot \mathrm{K}^{-1}\right)\end{array}$ \\
\hline Н3РО4 & 32.42 & & & \\
\hline $\mathrm{HCl}$ & 55.12 & & & \\
\hline H3PO4 and inhibitor & 98.68 & -139.01 & -23.28 & -0.38 \\
\hline $\mathrm{HCl}$ and inhibitor & 90.95 & -51.13 & -24.52 & -0.09 \\
\hline
\end{tabular}

\subsection{Thermodynamic Parameters}

After plotting the Langmuir adsorption isotherms for the inhibitor in the test solutions intercept of this graph is $1 / \mathrm{K}_{\mathrm{ads}}$, where $\mathrm{K}_{\mathrm{ads}}$ is the constant of adsorption equilibrium. After measuring $\mathrm{K}_{\mathrm{ads}}$, the value of 
free adsorption energy was calculated using the below equation.

$$
\Delta \mathrm{G}_{\mathrm{ads}}^{\mathrm{o}}=-\mathrm{RT} \ln \left(1 \times 10^{6} \mathrm{~K}_{\mathrm{ads}}\right)
$$

8

The values of $\Delta \mathrm{G}^{\circ}{ }_{(\mathrm{ads})}$ for the inhibitor in both environments are listed in Table 4.

Also, the following equation can be used to determine $\Delta \mathrm{H}^{\circ}$ ads $[28]$ :

$$
\frac{\theta}{1-\theta}=\mathrm{ACexp}\left(-\frac{\Delta \mathrm{H}_{\mathrm{ads}}^{\mathrm{o}}}{\mathrm{RT}}\right)
$$

9

Where $\mathrm{T}$ is the absolute temperature in kelvins, $\mathrm{A}$ is a constant, $\mathrm{C}$ is the inhibitory concentration, $\mathrm{R}$ is the gas constant, $\Delta \mathrm{H}^{\circ}$ ads the adsorption heat, and $\theta$ is the surface coating created by the inhibitory molecules.

$\operatorname{Ln}_{(\theta /(1-\theta)}$ is plotted versus 1/T (Fig. 8) for the highest concentration of the inhibitor in both solutions. The slope of the linear parts of the graph is $\left(-\Delta \mathrm{H}^{\circ}\right.$ ads) $\left.) / \mathrm{R}\right)$, which it is used to measure $\Delta \mathrm{H}^{\circ}$ (ads).

In addition, Eq. 10 is used to measure $\Delta \mathrm{S}_{\mathrm{ads}}^{\mathrm{o}}$ [29]:

$$
\Delta \mathrm{G}_{\mathrm{ads}}^{\mathrm{o}}=\Delta \mathrm{H}_{\mathrm{ads}}^{\mathrm{o}}-\mathrm{T} \Delta \mathrm{S}_{\mathrm{ads}}^{\mathrm{o}}
$$

10

The values of measured thermodynamic and kinetic factors are illustrated in Table 4.

The values of activationenergy $\left(E_{a}\right)$ withoutandwith the inhibitor have been shown in this table which suggests that the activation energy with the inhibitor has increased. Increasing the activation energy of corrosion with the inhibitor confirmed that inhibition is closely associated to the adsorption phenomenon [30]. The measured free adsorption energy $\left(\Delta \mathrm{G}_{\mathrm{ads}}^{\mathrm{O}}\right)$ for the inhibitor in two acidic media is more minor than $-40 \mathrm{~kJ} \mathrm{~mol}^{-1}$, in a range between the physical and chemical adsorption. It should be taken into account that the adsorption phenomenon is not expressed solely for a molecule that can be regarded as a complete form of physical or chemical adsorption phenomena. Still, for a large number of existing molecules, a range of adsorption behavior should be expected in which sometimes chemical adsorption or physical adsorption is overcoming [31]. The value of free adsorption energy $\left(\Delta \mathrm{G}_{\text {ads }}^{\mathrm{o}}\right)$ for the inhibitor in both media is negative, which shows that it is a spontaneous process [32]. Negative values of 
adsorption enthalpy $\left(\Delta \mathrm{H}_{\mathrm{ads}}^{\mathrm{O}}\right.$ ) of the inhibitor suggested that the adsorption of this inhibitor on the alloy for both media is an exothermic process. The values of adsorption entropy $\left(\Delta \mathrm{S}_{\mathrm{ads}}^{\mathrm{o}}\right)$ in the hydrochloride acid solution containing inhibitor was small and positive, indicating a slight increase in Entropy. This value in the phosphoric acid solution was small and negative, indicating a decrease in Entropy.

\subsection{Investigation of surface morphology}

Scanning electron micrographs (SEM) of the surface of mild steel alloy plunged in 0.5 M H3PO4 and $1 \mathrm{M}$ $\mathrm{HCl}$ solutions in the absence and the presence of $500 \mathrm{ppm}$ of drug for 24 hours are demonstrated in Figs. 9 and 10. Figures 9 and 10a show that without the inhibitor, the metal surface was corroded and has a plenty number of pits. In part $b$ of each figure (Fig. $9 \mathrm{~b}$ and 10b), it is observed that the addition of the inhibitor resulted in formation of somewhat a protective layer on the surface of the steel. This layer created a block on the metal surface and prevented corrosive ions to reach the metal surface and it also passivated the active points on the alloy surface. These figures presented the performance of the inhibitor at the alloy surface which avoided corrosion of the metal surface through making a protective layer.

\section{Conclusion}

1- The result from EIS and polarization measurements displayed that Phenazopyridine is appropriate inhibitor for mild steel in $1 \mathrm{M}$ hydrochloric acid and $0.5 \mathrm{M}$ phosphoric acid.

2-The inhibition efficiency of phenazopyridine for mild steel in $0.5 \mathrm{M}$ phosphoric acid is bigger than $1 \mathrm{M}$ hydrochloric acid.

3- Inhibition effectiveness raised with a rise in tablet concentration up to $500 \mathrm{ppm}$ but decreased with rise in temperature

4- The results acquired from polarization and EIS measurements were in good agreement.

5- The adsorption studies demonstrated that the adsorption of the inhibitor on the metal surface obeys the Langmuir adsorption isotherm.

6- The free energy and Enthalpy of adsorption indicate that the process were spontaneous and exothermic.

7-polarization measurements determined that the phenazopyridine is a mixed inhibitor in the hydrochloric acid solution and acts as an anodic inhibitor in the phosphoric acid solution.

8- SEM investigations also validate the adsorption performance of inhibitor.

\section{Declarations}




\section{Competing interests}

The authors declare no competing interests.

\section{Author contributions}

All authors conceived the experiments, R. N., Gh. S. and Z. G. performed the experiment, analyzed the data and results with support from Dr. S.M.A. H and all authors wrote the manuscript text.

\section{References}

1. Roberge, P.R., Handbook of corrosion engineering, McGraw-Hill 2000.

2. Abdel Ghany, N. Shehata, M. Saleh, R. El Hosary, A. Novel corrosion inhibitors for acidizing oil wells. Mater. Corros. 68 , 355-360 (2017).

3. C. R.I. Oviedo-Roa, Montiel-Sánchez, Vega-Paz, L.E. A., Marín-Cruz, J.s., Martinez-Magadan,J.-M., Theoretical study of the aliphatic-chain length's electronic effect on the corrosion inhibition activity of methylimidazole-based ionic liquids. Ind. Eng. Chem. Res. 55, 3506-3516 (2016).

4. Mirzakhanzadeh, Z. Kosari,A. Moayed, M. H., Naderi, R. Taheri, P. Mol, J. Enhanced corrosion protection of mild steel by the synergetic effect of zinc aluminum polyphosphate and 2mercaptobenzimidazole inhibitors incorporated in epoxy-polyamide coatings. Corros. Sci. 138 , $372-$ 379 (2018).

5. Dey, S. Chatterjee,S. Singh, B.P., Bhattacharjee, S. Rout,T.K., Sengupta, D.K., Besra, L. Development of superhydrophobic corrosion resistance coating on mild steel by electrophoretic deposition. Surf. Coat. Technol. 341, 24-30 (2018).

6. Li, L. Dong, C. Liu, L. Li, J. Xiao, K. Zhang, D. Li, X. Preparation and characterization of pH-controlledrelease intelligent corrosion inhibitor, Mater. Lett. 116, 318-321 (2014).

7. Yilmaz, N. Fitoz, A. Emregül, K. C., A combined electrochemical and theoretical study into the effect of 2-((thiazole-2-ylimino) methyl) phenol as a corrosion inhibitor for mild steel in a highly acidic environment, Corros. Sci. 111, 110-120 (2016).

8. Ghazoui, A. Saddik, R. Benchat, N. Guenbour, M. Hammouti, B. Al-Deyab, Zarrouk,S. A., Comparative study of pyridine and pyrimidine derivatives as corrosion inhibitors of C38 steel in molar $\mathrm{HCl}$, Int. J. Electrochem. Sci. 7, 7080-7097 (2012).

9. Ebenso, E. Effect of halide ions on the corrosion inhibition of mild steel in $\mathrm{H}_{2} \mathrm{SO}_{4}$ using methyl red: Part 1, Bull. Electrochem. 19, 209-216 (2003).

10. Xhanari, K. Finsgar, M. Hrnčič, M. K., Maver, U. Knez, Ž. Seiti, B.Green corrosion inhibitores for aluminium and its alloys:a review. RSC Adv. 7, 27299 (2017).

11. Gece, G. Drugs: a review of promising novel corrosion inhibitors, Corros. Sci. 53, 3873-3898 (2011). 
12. Abdallah, M. Antibacterial drugs as corrosion inhibitors for corrosion of aluminium in hydrochloric solution, Corros. Sci. 46, 1981-1996 (2004).

13. Eddy, N. Odoemelam, S. Ekwumemgbo, P. Inhibition of the corrosion of mild steel in $\mathrm{H}_{2} \mathrm{SO}_{4}$ by penicillin G, Sci. Res. Essays 4, 033-038 (2009).

14. Eddy, N. Odoemelam, S. Inhibition of the corrosion of mild steel in acidic medium by penicillin $\mathrm{V}$ potassium, Adv. Nat. Appl. Sci. 2, 225-233 (2008).

15. Fouda, A. El-Abbasy, H. Inhibitive action of ampicillin and benzyl penicillin drugs for corrosion of type 304 stainless steel in $1.0 \mathrm{M} \mathrm{HCl}$ solution, Corrosion. 68, (2012).

16. Kumar, S. H., Karthikeyan, S. Amoxicillin as an efficient green corrosion inhibitor for mild steel in $1 \mathrm{M}$ sulphuric acid, J. Mater. Environ. Sci 4, 675-984 (2013).

17. Nazeer, A. A., El-Abbasy,H. Fouda, A. Antibacterial drugs as environmentally-friendly corrosion inhibitors for carbon steel in acid medium, Res. Chem. Intermed. 39, 921-939 (2013).

18. Mahdi, A. S., Amoxicillin as green corrosion inhibitor for concrete reinforced steel in simulated concrete pore solution containing chloride, International Journal of Advanced Research in Engineering and Technology 5, 99-107 (2014).

19. Elkadi, L. Mernari, B. Traisnel, M. Bentiss, F. Lagrenee, M. The inhibition action of 3, 6-bis (2methoxyphenyl)-1, 2-dihydro-1, 2, 4, 5-tetrazine on the corrosion of mild steel in acidic media, Corros. Sci. 42, 703-719 (2000).

20. Sherif, E. M. Park, S. M., Inhibition of copper corrosion in acidic pickling solutions by N-phenyl-1, 4phenylenediamine, Electrochim. Acta 51, 4665-4673 (2006).

21. Wang, L. Inhibition of mild steel corrosion in phosphoric acid solution by triazole derivatives, Corros. Sci. 48, 608-616 (2006).

22. Bentiss, F. Traisnel, M. Lagrenee, M. The substituted 1, 3, 4-oxadiazoles: a new class of corrosion inhibitors of mild steel in acidic media, Corros. Sci. 42, 127-146 (2000).

23. Outirite, M. Lagrenée, M. Lebrini, M. Traisnel, M. Jama, C. Vezin, H. Bentiss, F. ac impedance, X-ray photoelectron spectroscopy and density functional theory studies of 3, 5-bis (n-pyridyl)-1, 2, 4oxadiazoles as efficient corrosion inhibitors for carbon steel surface in hydrochloric acid solution, Electrochim. Acta 55, 1670-1681 (2010).

24. Safizadeh, F. Lafront, A. M., Ghali, E. Houlachi,G. An investigation of the influence of selenium on copper deposition during electrorefining using electrochemical noise analysis, Hydrometallurgy 111, 29-34 (2012).

25. Hosseini, S. M., Azimi, A. The inhibition effect of the new Schiff base, namely 2, 2'-[bis-N (4-choloro benzaldimin)]-1, 1'-dithio against mild steel corrosion, Mater. Corros. 59, 41-45 (2008).

26. Eddy, N.O., Ekwumemgbo, P. Odoemelam, S. A., Inhibition of the corrosion of mild steel in $\mathrm{H}_{2} \mathrm{SO}_{4}$ by 5amino-1-cyclopropyl-7-[(3R, 5S) 3, 5-dimethylpiperazin-1-YL]-6, 8-difluoro-4-oxo-uinoline-3-carboxylic acid (ACPDQC), Int. J. Phys. Sci. 3, 275-280 (2008). 
27. El Mehdi, B. Mernari, B. Traisnel, M. Bentiss, F. Lagrenee, M. Synthesis and comparative study of the inhibitive effect of some new triazole derivatives towards corrosion of mild steel in hydrochloric acid solution, Mater. Chem. Phys. 77, 489-496 (2003).

28. Hosseini, S. M., Amiri, M. Momeni, A. Inhibitive effect of $\mathrm{L}-\mathrm{OH}$ on the corrosion of austenitic chromium-nickel steel in $\mathrm{H}_{2} \mathrm{SO}_{4}$ solution, Surf. Rev. Lett. 15, 435-442 (2008).

29. Zhang, Q. B., Hua,Y.X., Corrosion inhibition of mild steel by alkylimidazolium ionic liquids in hydrochloric acid, Electrochim. Acta 54, 1881-1887 (2009).

30. Bouklah,M. Hammouti, B. Lagrenee, M. Bentiss, F. Thermodynamic properties of 2, 5-bis (4methoxyphenyl)-1, 3, 4-oxadiazole as a corrosion inhibitor for mild steel in normal sulfuric acid medium, Corros. Sci. 48, 2831-2842 (2006).

31. Vashi, R.T., Champaneri, V.A., Toluidines as corrosion inhibitors for zinc in sulphamic acid, Indian J. Chem.Technol 1, 180-184 (1997).

32. Qu, Q. Hao, Z. Jiang, S. Li, L. Bai, W. Synergistic inhibition between dodecylamine and potassium iodide on the corrosion of cold rolled steel in $0.1 \mathrm{M}$ phosphoric acid, Mater. Corros. 59, 883-888 (2008).

\section{Figures}

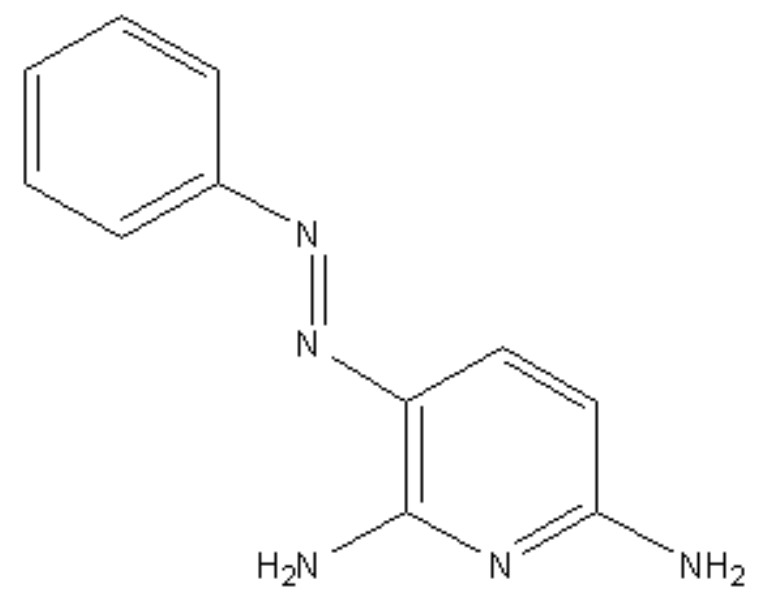

\section{Figure 1}

Molecular structure of phenazopyridine 


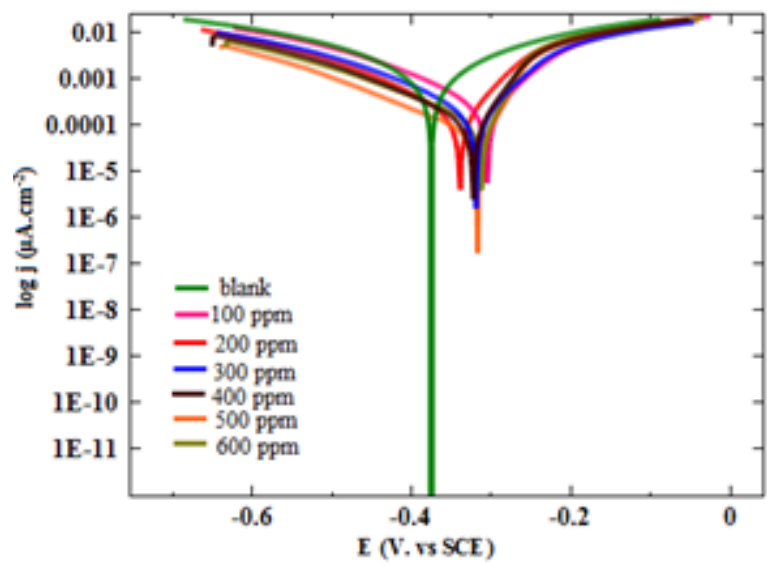

a

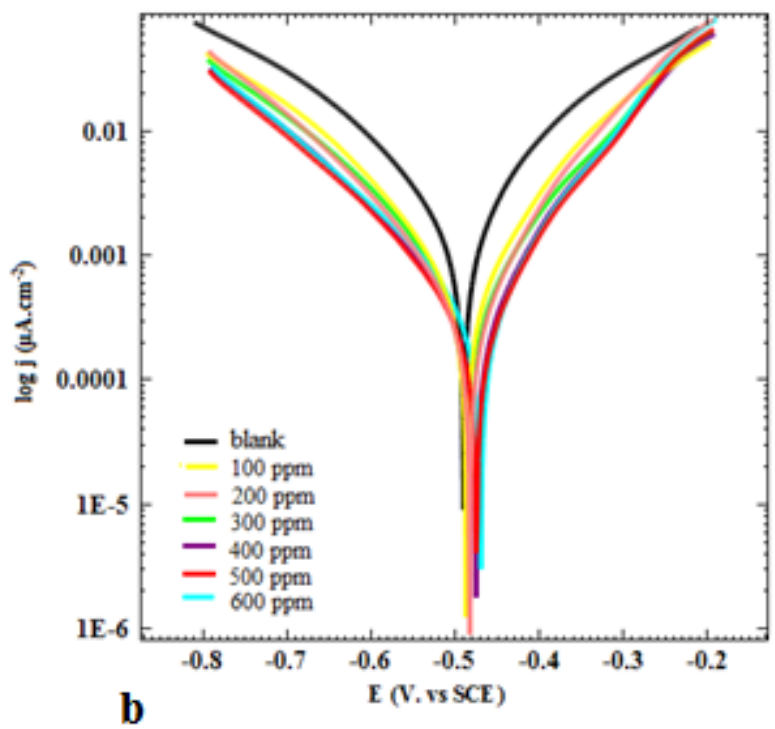

Figure 2

Polarization curves for mild steel in a) $0.5 \mathrm{M}$ phosphoric acid solution and b) $1 \mathrm{M}$ hydrochloric acid solution in absence and presence of different concentrations of inhibitor at $25^{\circ} \mathrm{C}$
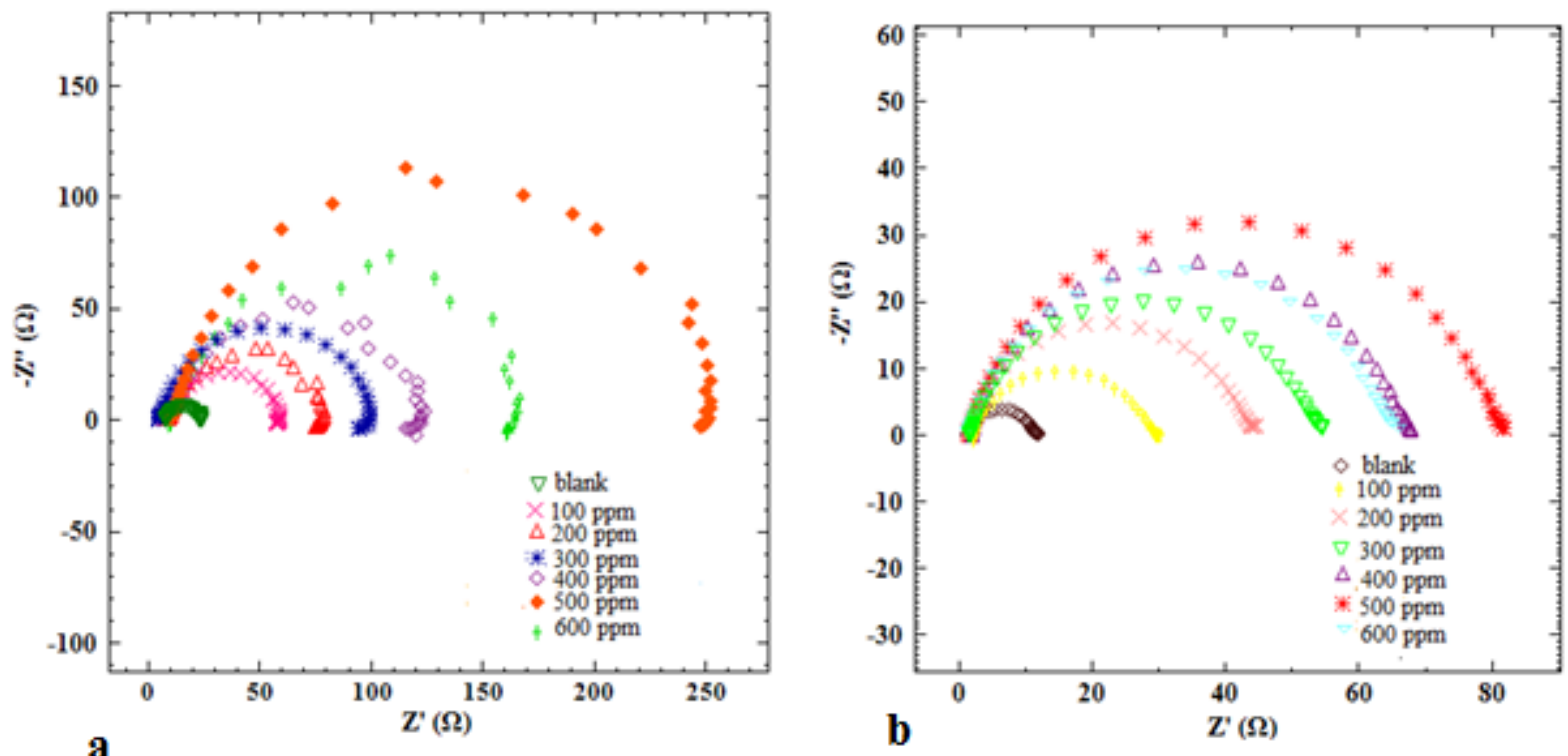

Figure 3

Nyquist curves for mild steel in a) $0.5 \mathrm{M}$ phosphoric acid solution and b) $1 \mathrm{M}$ hydrochloric acid solution in absence and presence of different concentrations of inhibitor at $25^{\circ} \mathrm{C}$ 


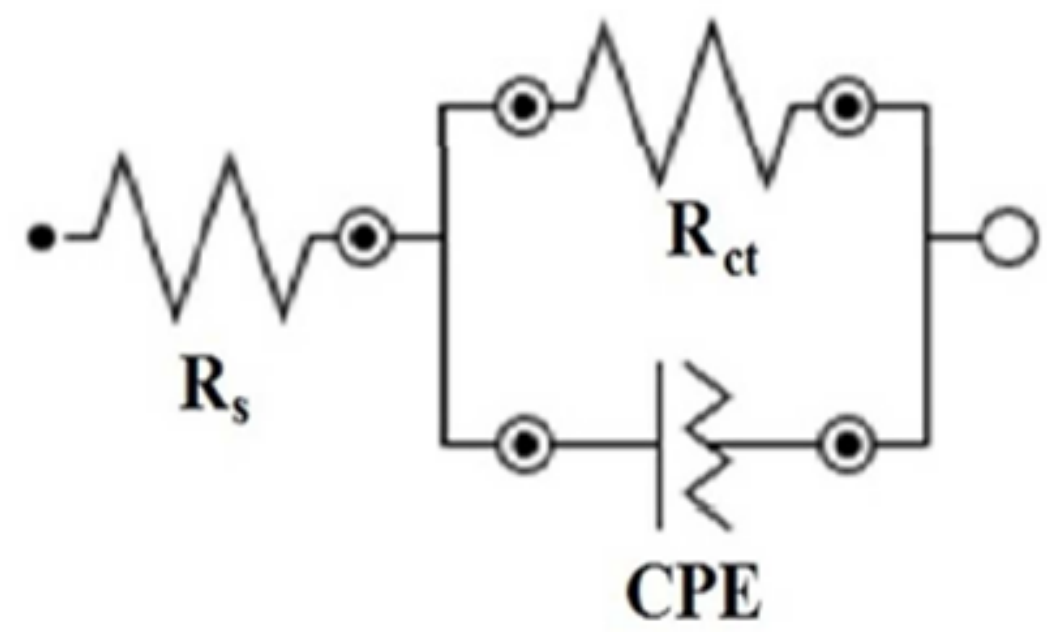

Figure 4

Equivalent circuit to estimate impedance diagrams
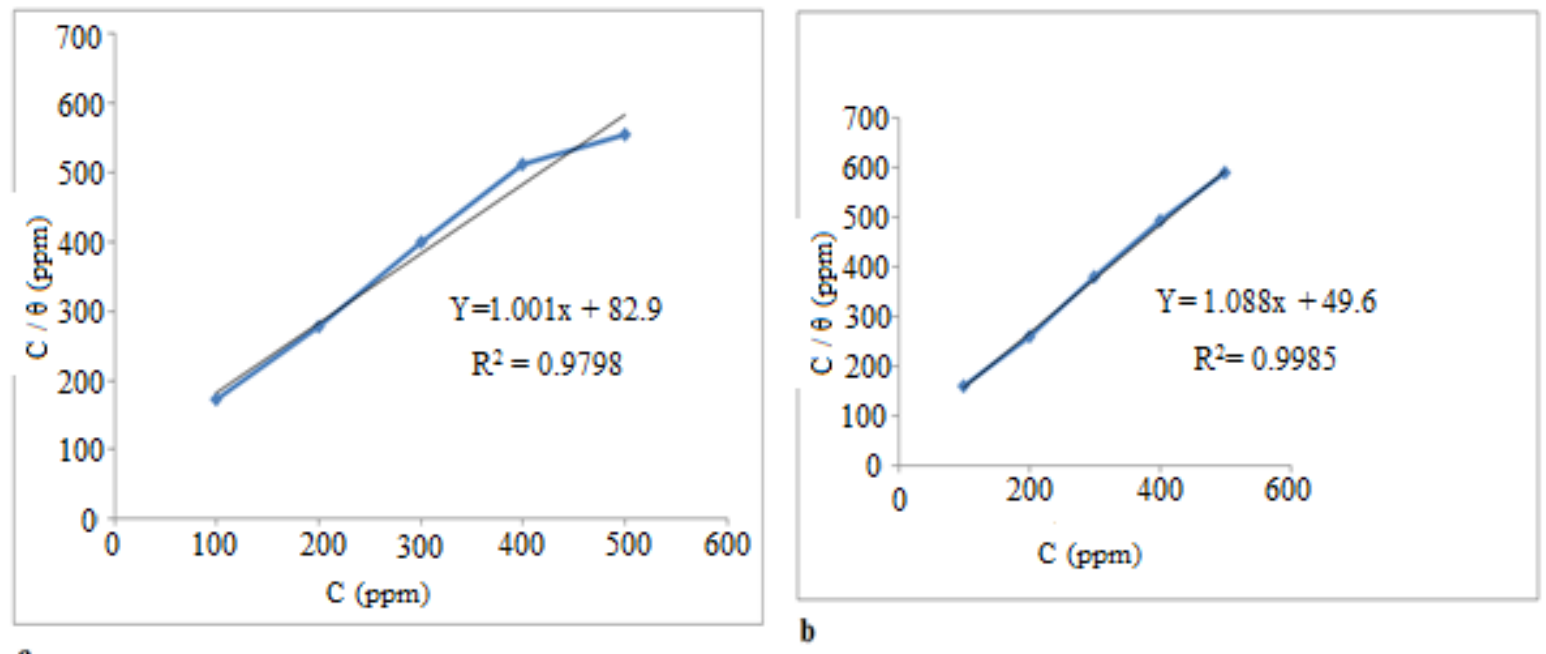

a

\section{Figure 5}

Langmuir adsorption isotherm on the mild steel surface in a) phosphoric acid and b) hydrochloric acid solution in the presence of inhibitor at $25^{\circ} \mathrm{C}$ 

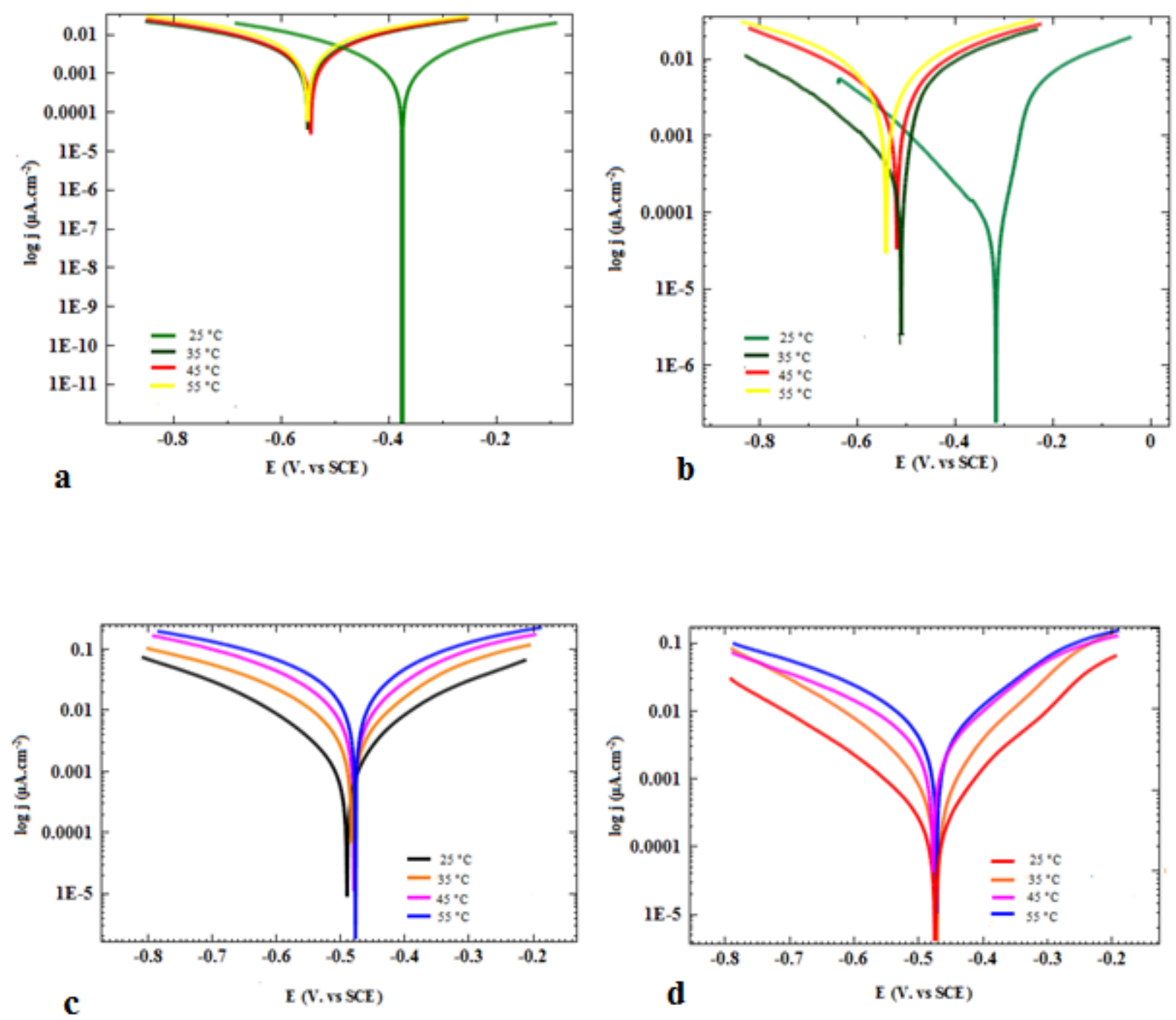

Figure 6

Effect of temperature on the polarization curves in $0.5 \mathrm{M}$ phosphoric acid solution a) without inhibitor b) with $500 \mathrm{ppm}$ of inhibitor and $1 \mathrm{M}$ hydrochloric acid solution c) without inhibitor d) with $500 \mathrm{ppm}$ of inhibitor 

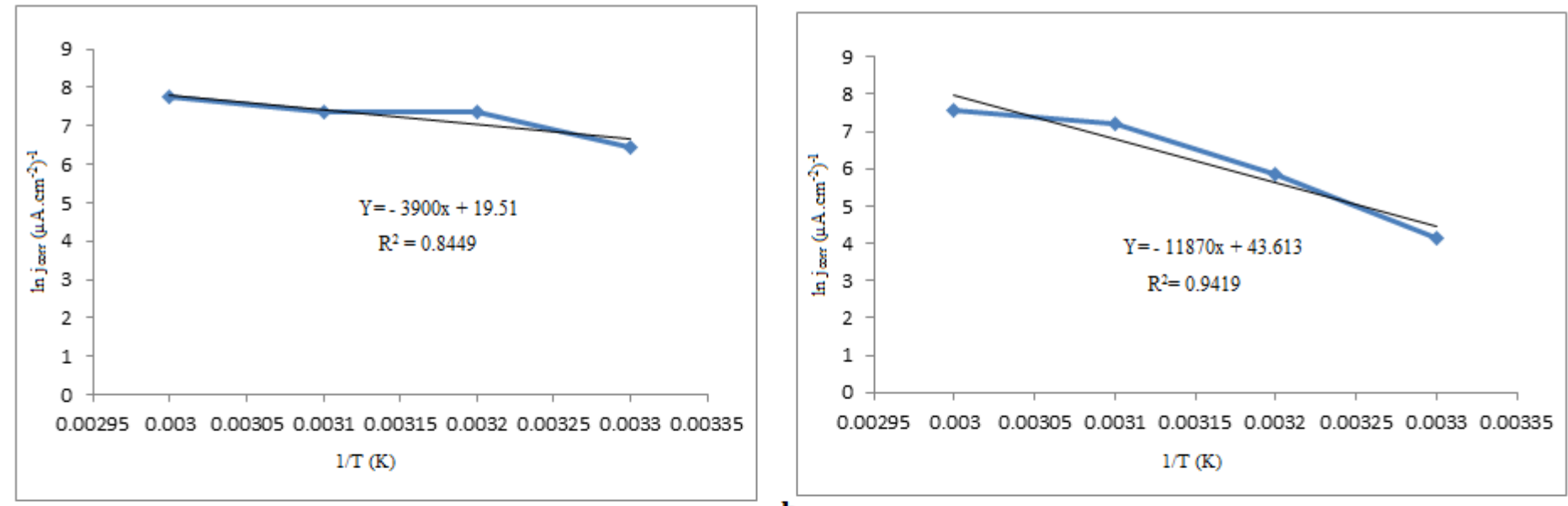

a

b
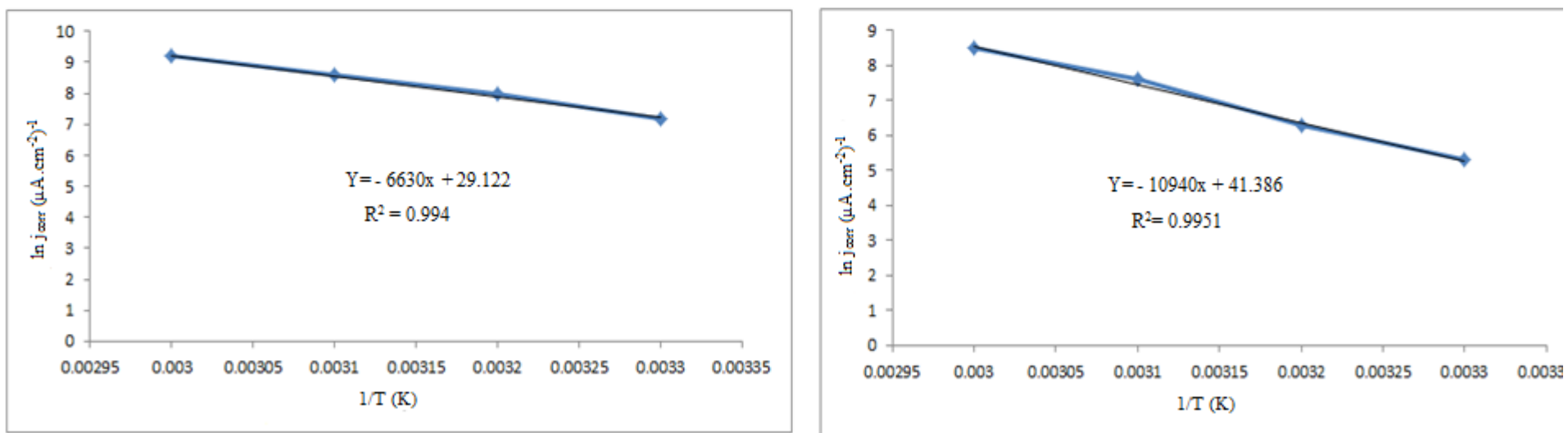

c

d

\section{Figure 7}

Arrhenius slopes calculated from corrosion current density for mild steel in $0.5 \mathrm{M}$ phosphoric acid solution, a) without inhibitor, b) with inhibitor and $1 \mathrm{M}$ hydrochloric acid solution $\mathrm{c}$ ) without inhibitor $\mathrm{d}$ ) with inhibitor

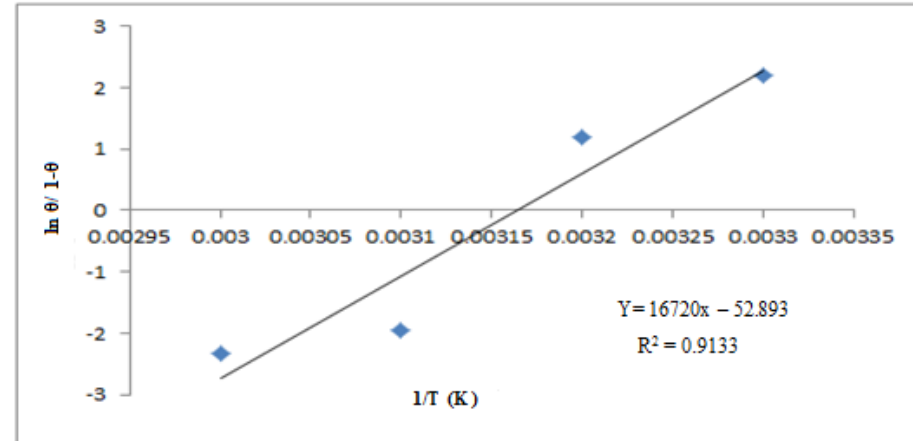

a

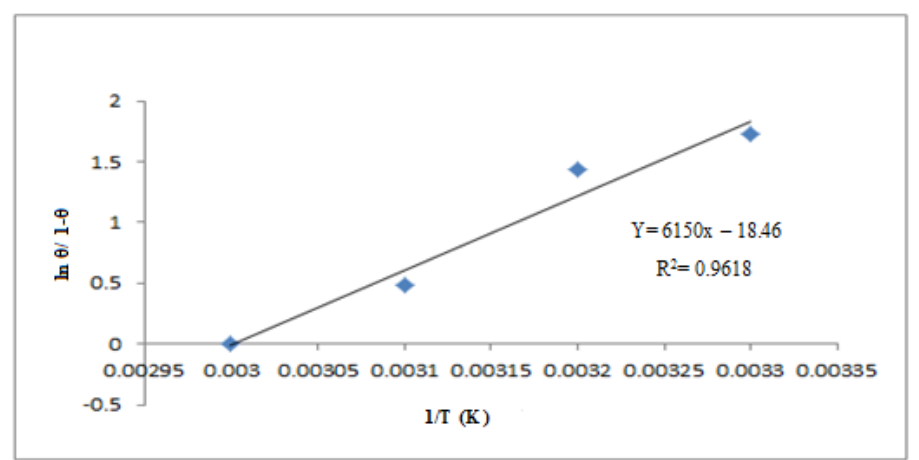




\section{Figure 8}

Plots of $\operatorname{Ln}(\theta / 1-\theta)$ versus $1 / T$ for mild steel in a) solution phosphoric acid solution containing $500 \mathrm{ppm}$ of inhibitor and $\mathrm{b}$ ) hydrochloric acid solution containing 500ppm of inhibitor, at different temperatures
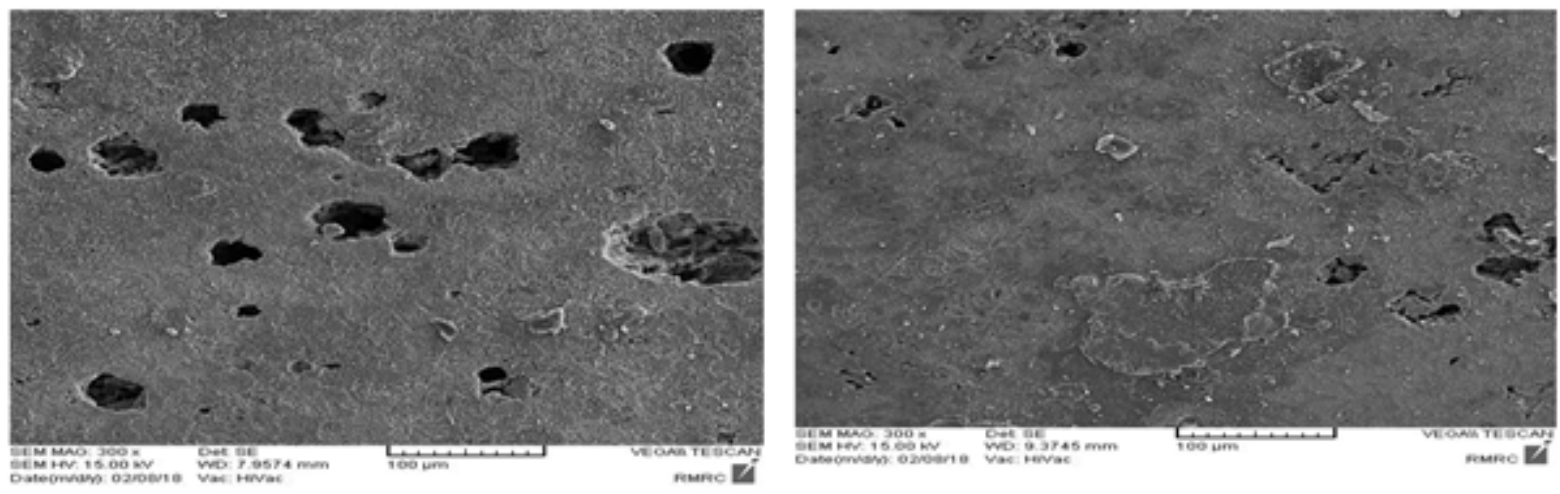

a

b

\section{Figure 9}

SEM images of mild steel in $0.5 \mathrm{M}$ phosphoric acid solution, a) blank, b) with inhibitor

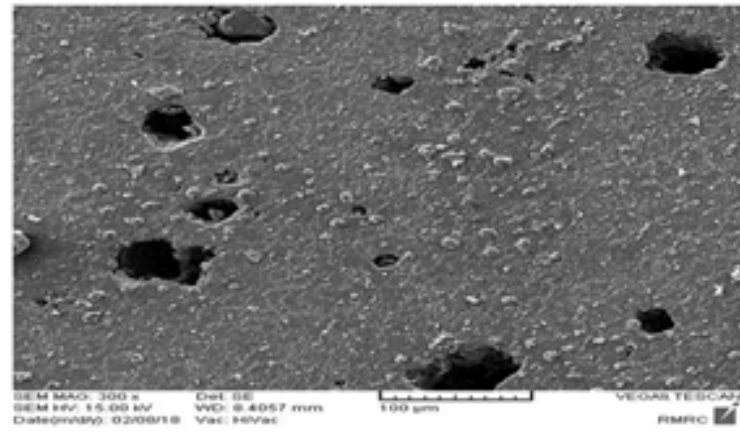

a

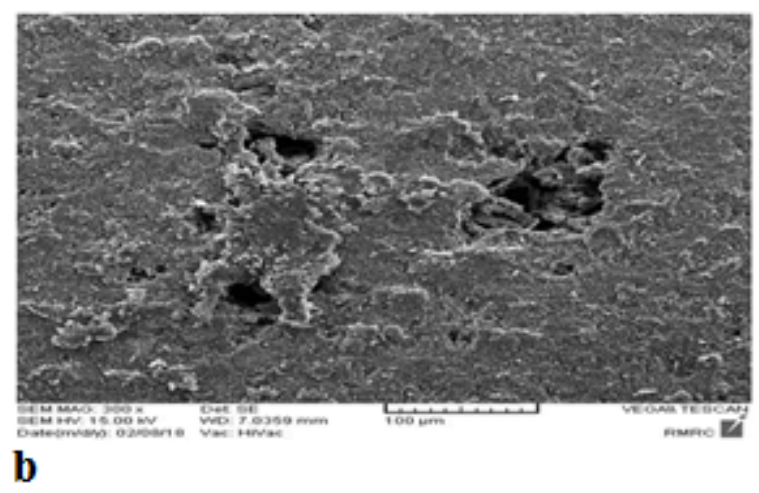

b

Figure 10

SEM images of mild steel in 1.0 M hydrochloric acid solution, a) blank, b) with inhibitor 